\title{
The histopathological spectrum of malignant hyperthermia and rhabdomyolysis due to RYR1 mutations
}

\author{
G. J. Knuiman ${ }^{1}$ - B. Küsters ${ }^{1}$ - L. Eshuis ${ }^{1} \cdot$ M. Snoeck ${ }^{2} \cdot$ M. Lammens $^{3} \cdot$ L. Heytens $^{4} \cdot$ W. De Ridder ${ }^{5,6,7} \cdot$ J. Baets ${ }^{5,6,7}$. \\ R. S. Scalco ${ }^{8} \cdot$ R. Quinlivan ${ }^{8}$. J. Holton ${ }^{8} \cdot$ I. Bodi $^{9}$ - E. Wraige ${ }^{9}$. A. Radunovic ${ }^{10}$. C. von Landenberg ${ }^{11}$. J. Reimann ${ }^{11}$. \\ E.-J. Kamsteeg ${ }^{12} \cdot$ C. Sewry ${ }^{13} \cdot$ H. Jungbluth ${ }^{9,14,15} \cdot$ N. C. Voermans ${ }^{16}$
}

Received: 25 November 2018 / Revised: 16 January 2019 / Accepted: 19 January 2019 / Published online: 20 February 2019

(c) The Author(s) 2019

\begin{abstract}
Objective The histopathological features of malignant hyperthermia (MH) and non-anaesthetic (mostly exertional) rhabdomyolysis (RM) due to RYRl mutations have only been reported in a few cases.

Methods We performed a retrospective multi-centre cohort study focussing on the histopathological features of patients with MH or RM due to RYR1 mutations (1987-2017). All muscle biopsies were reviewed by a neuromuscular pathologist. Additional morphometric and electron microscopic analysis were performed where possible.

Results Through the six participating centres we identified 50 patients from 46 families, including patients with MH $(n=31)$ and RM $(n=19)$. Overall, the biopsy of $90 \%$ of patients showed one or more myopathic features including: increased fibre size variability $(n=44)$, increase in the number of fibres with internal nuclei $(n=30)$, and type I fibre predominance $(n=13)$. Abnormalities on oxidative staining, generally considered to be more specifically associated with $R Y R l$-related congenital myopathies, were observed in 52\%, and included unevenness $(n=24)$, central cores $(n=7)$ and multi-minicores $(n=3)$. Apart from oxidative staining abnormalities more frequently observed in $\mathrm{MH}$ patients, the histopathological spectrum was similar between the two groups. There was no correlation between the presence of cores and the occurrence of clinically detectable weakness or presence of (likely) pathogenic variants.

Conclusions Patients with RYRl-related MH and RM exhibit a similar histopathological spectrum, ranging from mild myopathic changes to cores and other features typical of $R Y R I$-related congenital myopathies. Suggestive histopathological features may support $R Y R I$ involvement, also in cases where the in vitro contracture test is not informative.
\end{abstract}

Keywords RYR1 $\cdot$ RyR1 $\cdot$ Rhabdomyolysis $\cdot$ Malignant hyperthermia (MH) $\cdot$ Muscle biopsy $\cdot$ Histology.

\section{Introduction}

Mutations in the skeletal muscle ryanodine receptor $(R Y R I)$ gene are amongst the most common causes of non-dystrophic neuromuscular disorders [1], and associated with a

G. J. Knuiman and B. Küsters shared first authorship.

H. Jungbluth and N. C. Voermans shared senior authorship.

Electronic supplementary material The online version of this article (https://doi.org/10.1007/s00415-019-09209-z) contains supplementary material, which is available to authorized users.

N. C. Voermans

Nicol.voermans@radboudumc.nl

Extended author information available on the last page of the article wide clinico-pathological spectrum. RYRI encodes RyR1, the principal sarcoplasmic reticulum calcium release channel with a crucial role in excitation-contraction coupling. Dominant RYRl mutations were originally implicated in two distinct but occasionally overlapping human disorders, Central Core Disease (CCD), a congenital myopathy named after the typical core structures with reduced oxidative stains on muscle biopsy, and the Malignant Hyperthermia Susceptibility (MHS) trait, a pharmacogenetic predisposition to potentially life-threatening episodes of muscle breakdown and metabolic decompensation in response to volatile anaesthetics and/or the neuromuscular blocking agent succinylcholine.

The last two decades have seen an ever-increasing expansion of the RYRI-associated phenotypic spectrum: in addition to dominantly inherited CCD, other (mainly recessively inherited) congenital myopathies named after the 
predominant finding on muscle biopsy-Multi-minicore Disease (MmD) [2], Centronuclear Myopathy (CNM) [3], and Congenital Fibre Type Disproportion (CFTD) - have been described [4]. More recently, the clinical spectrum of predominantly MHS-associated RYR1 mutations has also further expanded, and was found to include other episodic phenotypes such as exertional myalgia associated with rhabdomyolysis (RM) [5] and periodic paralysis [6, 7], but also a distinct late-onset axial myopathy $[8,9]$ in previously healthy individuals.

Whilst the histopathological spectrum of $R Y R I$-associated congenital myopathies has been characterized extensively (for review: Jungbluth et al. [1]) [3, 4, 10-12], there is little information concerning the histopathological spectrum of $\mathrm{MH}-$ and RM-associated RYR1 mutations. Moreover, many of the reports concerning histopathological features in MH and RM predate their genetic resolution [13-18]. The relative scarcity of $\mathrm{MH}$-related histopathological data in particular may reflect that $\mathrm{MH}$ is essentially a clinical diagnosis, and that muscle biopsies in these patients are mainly performed for the purpose of a diagnostic halothane-caffeine in vitro contracture test (IVCT) rather than for primary histopathological evaluation. The few available reports suggest some overlap with the milder end of the $R Y R I$-associated congenital myopathy spectrum, or even a normal muscle biopsy appearance [5, 19-21]. The only large retrospective study on histopathological changes in MH included 399 MHS patients, of whom 86 (22\%) patients had histological abnormalities. However, only $226(57 \%)$ patients were genetically tested, and of them, only 86 (38\%) had a confirmed RYRI mutation [22].

In the present study, we, therefore, focused on genetically confirmed cases. We reviewed the muscle biopsy findings from 50 paediatric and adult patients presenting with $R Y R I$-associated MH or RM. We have delineated the key histopathological features, also in comparison to the already recognized $R Y R 1$-associated congenital myopathy spectrum, and have tried to establish tentative genotype-phenotype correlations on the histopathological level. We have emphasized histopathological features that should raise the possibility of $R Y R l$ involvement, in particular in episodic phenotypes such as RM, a very common presentation with many potential genetic causes but often no specific clinical signs [23].

\section{Patients and methods}

\section{Methods}

We performed a retrospective multi-centre cohort study focussing on the histopathological features of children and adults with $\mathrm{MH}$ or RM in whom an RYRl mutation was detected and a diagnostic muscle biopsy had been performed (1983-2017; RYR1 sequencing since 2006). RM was defined as an acute muscle breakdown in response to an external trigger [such as exercise, (recreational) drugs, medication, viral illness] associated with symptoms of myalgia, swelling, muscle weakness and/or myoglobinuria, reflected by a sudden rise (at least 10 times the upper normal limit for sex and ethnicity) and subsequent normalisation of CK levels. Biopsies had been taken at least 2 months after the $\mathrm{MH}$ or RM episode, except in patient 34 and 46, in whom the biopsy had been taken in the acute RM phase.

The study protocol was approved by the Radboud UMC Ethics Committee (2017-3903).

\section{Patients}

Key clinical (but not histopathological) features from 34 patients included in this study have already been reported by Snoeck et al. and Dlamini at al. (Supplementary File 1) $[5,21]$. In the current study, muscle biopsies were included for review from additional patients seen at tertiary $\mathrm{MH}$ and neuromuscular referral centres: Antwerp University Hospital (Belgium), University of Bonn Medical Centre (Germany), Radboud University Medical Centre (The Netherlands), Evelina Children's Hospital, London, The National Hospital for Neurology and Neurosurgery (NHNN), and the Royal London Hospital, London (United Kingdom). Relatives carrying the familial RYRI mutation (with a positive IVCT) were also included. Patients were only included if the original muscle biopsy slides were available for (re)evaluation. The following data were collected: clinical diagnosis, presumed mode of inheritance, presence of muscle weakness, and result of IVCT. The IVCT had been performed (partly in the pregenetic era) in patients who later proved to have a diagnostic MH mutation (see below), according to the European Malignant Hyperthermia Group (EMHG) protocol (https ://www.emhg.org/testing-for-mh/2017/12/28/in-vitro-contr acture-testing-ivct).

\section{Molecular genetic studies}

The coding regions (exons 1-106) of the RYRl gene, including splice sites, were screened at the genomic level by standard Sanger sequencing or panel sequencing (RM panel since 2014 [23]). Haplotyping of unrelated patients carrying the recurrent $R Y R I$ mutation c.12861_12869dup (p.Thr4288_Ala4290dup) was carried out using a panel of highly polymorphic microsatellite repeat markers located in and around the RYRI locus [3, 5]. Until 2008, MH patients had first been tested by multiplex ligation-dependent probe amplification (MLPA) using two kits containing the first 27 functionally characterized diagnostic $\mathrm{MH}$ mutations (i.e., functionally fully characterized $R Y R I$ mutation recognized 
as MH causative; http://www.emhg.org/diagnostic-mutat ions) supplemented with six recurrent non-functionally characterized mutations [21]. Relatives were investigated for the presence of the familial mutations only. For all RYRI mutations it was checked whether they were diagnostic MH mutations according to the EMGH; if not, variants were classified according to current American College of Medical Genetics and Genomics (ACMG) guidelines as pathogenic, likely pathogenic, variant of undetermined significance (VUS) or likely benign [24, 25]. Results of other genetic tests in patients with RM were also collected.

\section{Histopathological studies}

The neuromuscular pathologists (JK and BK at Radboudumc and $\mathrm{JH}$ at NHNN) reviewed the standard histological [hematoxylin and eosin, H\&E, Gomori trichrome, periodic acidSchiff (PAS), sudan black or oil red O] and histochemical [nicotinamide adenosine dinucleotide-tetrazolium reductase (NADH-TR); succinate dehydrogenase (SDH), ATPase, preincubated at $\mathrm{pH}$ 10.3, 4.6 and 4.3; cytochrome c oxidase, (COX) stains as available]. (In all cases at least a hematoxylin and eosin staining and an oxidative stain were available for review.) Cores and minicores were defined as previously reported [10]. Type 1 predominance was defined as $\geq 55 \%$ type 1 fibres [26]. Fibre type disproportion was qualitatively evaluated on the basis of the ATPase pre-incubated at a $\mathrm{pH}$ of 4.2-staining. Increased fibre size variation was defined as an increased ratio $(>2)$ between largest and smallest fiber size [26]. After individual evaluation of each biopsy, consensus was reached by open discussion. Electron microscopy reports were reviewed where available $(n=27 ; 54 \%$ of patients).

\section{Statistics}

The difference in occurrence of specific histopathological features in patients with $\mathrm{MH}$ and $\mathrm{RM}$ were compared by a Chi-square test. The age difference between groups with and without cores was calculated by an independent $T$ test.

\section{Results}

\section{Patients and biopsies}

We identified 50 patients from 46 families, including $31 \mathrm{MH}$ cases (16 index patients and 15 first-degree adult relatives carrying the familial $R Y R I$ variant with a postivie IVCT who had volunteered to undergo the IVCT instead of the mostly paediatric index patient) and 19 individuals who had suffered from RM. One patient (patient 38) within the RM group had an initial episode of exertional RM followed by an $\mathrm{MH}$ event. Four pairs of related patients were included (patients 6 and 7,15 and 16, 23 and 24 in the MH group, and 32 and 33 in the RM group). All RM patients had one or more features suggesting an underlying genetic cause [recurrent episodes of exertional rhabdomyolysis; hyperCKaemia persisting 8 weeks after the event; RM occurring after accustomed physical exercise; blood CK $>50 \times$ upper limit of normal ( $>10,000$ ULN in female Caucasian patients); absence of drugs/medication/supplements that could explain the rhabdomyolysis; and/or other family members affected, or other exertional symptoms (cramps, myalgia)] [27] Recurrent episodes were reported in 9 of 13 patients. Needle or open biopsies were taken from the quadriceps muscle (mostly vastus lateralis) unless specified otherwise (Supplementary File 2).

Clinical findings are summarized in Table 1 . There was predominance of male patients (74\%; 20/31 MH and 17/19 $\mathrm{RM})$. Likely triggers for RM were: heat $(n=2)$, infection $(n=2)$ and exertion $(n=17)$; in addition, one RM patient each had a history of statin use and hypothyroidism, respectively. In 37 patients, an IVCT was performed (31 patients with $\mathrm{MH}$; six patients with $\mathrm{RM}$ ); this was positive in all $\mathrm{MH}$ patients but only in two of six patients with RM. Eleven patients had fixed muscle weakness (22\%; three with $\mathrm{MH}$; eight with RM) (Supplemental table 1). This included mild proximal, predominantly hip girdle weakness $(\mathrm{MRC} \geq 4$; $n=7)$, ptosis $(n=3)$, facial weakness $(n=2)$ and/or scapular winging $(n=1)$. The two patients with mild facial weakness had remarkable muscle hypertrophy. Two patients had a combination: ptosis or facial weakness with mild proximal weakness. None of the patients had considered those as significant disease symptoms. One patient developed paraparesis following spinal cord injury.

\section{Molecular genetic studies}

The results of the genetic analysis are shown in Table 2: In 30 patients, a diagnostic MH mutation as defined by the EMHG was detected ( 26 of 30 with $\mathrm{MH}$, and in 4 of 18 with RM). Recurrent mutations were: c. $1021 \mathrm{G}>\mathrm{A}$ (p.Gly341Arg) $(n=5 \mathrm{MH})$, c.1840C $>$ T (p.Arg614Cys) ( $n=4$ MH), c.12861_12869dup (p.Thr4288_Ala4290dup) $(n=3 \mathrm{RM}), \mathrm{c} .7025 \mathrm{~A}>\mathrm{G}$ (p.Asn2342Ser) $(n=1 \mathrm{MH} ; n=1$ RM), c.7300G > A (p.Gly2434Arg) $(n=5 ; 2 \mathrm{MH}$ and 3 $\mathrm{RM})$, and c. $14545 \mathrm{G}>\mathrm{A}$ (p.Val4849Ile) $(n=10 ; 9 \mathrm{MH}$ and $1 \mathrm{RM}$ in combination with a second mutation). In addition, two patients had an allele with three RYRI mutations previously described [28]. In total, 30 patients had one or two pathogenic mutation(s) (26 with MH; 4 with RM), in three patients the mutation(s) was likely pathogenic (three with $\mathrm{RM}$ ), and in 17 the mutation(s) were classified as a VUS (five with MH; 12 with RM). Supplemental file 1 shows the 
Table 1 Summary of clinical features and results of histological analysis

\begin{tabular}{|c|c|c|c|}
\hline & $\mathrm{MH}$ and $\mathrm{RM}$ & MH & $\mathrm{RM}$ \\
\hline Clinical features & $n=50(\%)$ & $n=31(\%)$ & $n=19(\%)$ \\
\hline Sex: male & $37(74)$ & $20(65)$ & $17(89)$ \\
\hline $\begin{array}{l}\text { Positive IVCT (MHS or MHE) or diagnostic MH mutation } \\
\text { (according to EMHG) }\end{array}$ & $35(70)$ & $31(100)$ & $4(21)$ \\
\hline Permanent muscle weakness & $11(22)$ & $3(10)$ & $8(42)$ \\
\hline Histopathological analysis & $n=50$ & $n=31$ & $n=19$ \\
\hline Mean age at biopsy (range) & $34(5-67)$ & $37(10-67)$ & $31(5-61)$ \\
\hline Normal & $5(10)$ & $3(10)$ & $2(11)$ \\
\hline General myopathic features & $45(90)$ & $28(90)$ & $17(89)$ \\
\hline Increased fibre size variability & $44(88)$ & $27(87)$ & $17(89)$ \\
\hline Increased number of fibres with internal nuclei $(>3 \%)$ & $30(60)$ & $20(65)$ & $10(53)$ \\
\hline $\begin{array}{l}\text { Increased number of fibres with central nuclei (part of } \\
\text { group above) }\end{array}$ & $18(36)$ & $13(42)$ & $5(26)$ \\
\hline Type 1 fibre predominance & $13(26)$ & $7(23)$ & $6(32)$ \\
\hline Prominent lipid vacuoles ${ }^{(1)}$ & $3(6)$ & $0(0)$ & $3(16)$ \\
\hline Necrotic fibres ${ }^{(2)}$ & $3(6)$ & $0(0)$ & $3(3)$ \\
\hline Mild increase in connective tissue in endomysium & $2(4)$ & $1(3)$ & $1(5)$ \\
\hline Abnormalities on oxidative staining & $26(52)$ & $18(58)$ & $8(42)$ \\
\hline Unevenness $^{(3)}$ & $24(48)$ & $20(65)$ & $4(21)$ \\
\hline Central cores & $7(14)$ & $6(19)$ & $1(5)$ \\
\hline Ring -fibres & $4(8)$ & $2(6)$ & $2(11)$ \\
\hline Multiple minicores & $3(6)$ & $2(6)$ & $1(5)$ \\
\hline \multicolumn{4}{|l|}{ Abnormalities on trichome staining } \\
\hline Nemaline rods & $1(2)$ & $1(3)$ & $0(0)$ \\
\hline Electron microscopy (EM) & $n=26$ & $n=16$ & $n=10$ \\
\hline Normal & $4(15)$ & $3(19)$ & $1(10)$ \\
\hline Abnormal & $22(85)$ & $13(81)$ & $9(90)$ \\
\hline Z-band streaming & $8(31)$ & $6(38)$ & $2(20)$ \\
\hline Cores (central cores or minicores) & $8(31)$ & $6(38)$ & $2(20)$ \\
\hline Abnormal mitochondria & $4(15)$ & $1(6)$ & $3(30)$ \\
\hline Lipid droplets & $1(4)$ & $0(0)$ & $1(10)$ \\
\hline Combined analysis of LM an and EM ${ }^{\mathrm{a}}$ & $n=50$ & $n=31$ & $n=19$ \\
\hline Cores (central cores or minicores) & $14(28)$ & $11(35)$ & $3(16)$ \\
\hline Central cores $^{\mathrm{a}}$ & $8(16)$ & $7(23)$ & $1(5)$ \\
\hline Multiple minicores $^{b}$ & $6(12)$ & $4(13)$ & $2(11)$ \\
\hline
\end{tabular}

${ }^{\mathrm{a}}$ Central cores were observed by light microscopy (LM) in patients 3, 4, 11, 19, 20, 24 (all MH) and 35 (rhabdomyolysis); and on EM in patients 19, 24, 29 (all MH), and 35 (rhabdomyolysis)

${ }^{\mathrm{b}}$ Multiple minicores were observed by LM in patients 21 and $27(\mathrm{MH})$ and 47 (rhabdomyolysis), and on EM in patients 5, 27, $31(\mathrm{MH}), 44$ and 47 (rhabdomyolysis)

${ }^{(1)}$ and ${ }^{(2)} p=0.02$ (Chi-square test)

${ }^{(3)} p<0.05$ (Chi-square test)

additional genetic tests that were performed and showed no other genetic cause for the RM.

In all but one patient the (presumed) mode of inheritance was AD. Patient 34, who suffered from a severe episode of heat- and exercise-induced rhabdomyolysis with severe encephalomyelopathy, resulting in a permanent spinal cord lesion, had two RYRl variants on separate alleles [c.2488C $>\mathrm{T}$ (p.Arg830Trp),c.10219G > A
(p.Ala3407Thr)]. His parents, both carrier of one of the alleles, had no neuromuscular symptoms and normal CK. Supplemental table 1 shows the results of genetic testing of the individual patients. 
Table 2 Summary of genetic analysis

\begin{tabular}{|c|c|c|c|c|c|c|}
\hline Mutation & $\begin{array}{l}\text { Num- } \\
\text { ber of } \\
\text { patients }\end{array}$ & $\begin{array}{l}\text { Number of } \\
\text { patients with } \\
\text { MH }\end{array}$ & $\begin{array}{l}\text { Number of } \\
\text { patients with } \\
\text { RM }\end{array}$ & $\begin{array}{l}\text { (Allele with) } \\
\text { diagnostic } \mathrm{MH} \\
\text { mutation }\end{array}$ & $\begin{array}{l}\text { Classification of patho- } \\
\text { genicity for MH (or for } \\
\text { congenital myopathy in } \\
\text { case of }^{\text {a) }} \text { ) }\end{array}$ & $\begin{array}{l}\text { Previous report of this } \\
\text { case } \\
\text { First report; functional } \\
\text { characterization }\end{array}$ \\
\hline $\begin{array}{l}\text { c.1021G > A } \\
\text { (p.Gly341Arg) }\end{array}$ & 5 & 5 & & Yes & Pathogenic & Quane [29]; Tong [30] \\
\hline $\begin{array}{l}\text { c. } 1522 \mathrm{G}>\mathrm{C} \\
\text { (p.Glu508Gln) }\end{array}$ & 1 & & 1 & No & VUS & This report \\
\hline $\begin{array}{l}\text { c. } 1597 \mathrm{C}>\mathrm{T} \\
\text { (p.Arg533Cys) }\end{array}$ & 1 & & 1 & No & Likely pathogenic & Tammaro [31]; Sato [32] \\
\hline $\begin{array}{l}\text { c. } 1840 \mathrm{C}>\mathrm{T} \\
\text { (p.Arg614Cys) }\end{array}$ & 4 & 4 & & Yes & Pathogenic & Gillard [33]; Girard [34] \\
\hline $\begin{array}{l}\text { c. } 1840 \mathrm{C}>\mathrm{T} \\
\text { (p.Arg614Cys) } \\
\text { c.14364+1G }>\mathrm{T} \text { (on } \\
\text { two alleles) }\end{array}$ & 1 & 1 & & $\begin{array}{l}\text { Yes } \\
\text { No }\end{array}$ & $\begin{array}{l}\text { Pathogenic } \\
\text { Pathogenic }\end{array}$ & $\begin{array}{l}\text { Gillard [33] for first } \\
\text { mutation } \\
\text { Girard [34]/Snoeck [21] } \\
\text { for second mutation }\end{array}$ \\
\hline $\begin{array}{l}\text { c. } 1840 \mathrm{C}>\mathrm{T} \\
\text { (p.Arg614Cys) } \\
\text { c. } 8026 \mathrm{C}>\mathrm{T} \\
\text { (p.Arg2676Trp) (on } \\
\text { two alleles) }\end{array}$ & 1 & 1 & & $\begin{array}{l}\text { Yes } \\
\text { No }\end{array}$ & $\begin{array}{l}\text { Pathogenic } \\
\text { Likely pathogenic }\end{array}$ & $\begin{array}{l}\text { Gillard [33]; Girard [34] } \\
\text { for first mutation } \\
\text { Guis (2004) [35] for } \\
\text { second mutation }\end{array}$ \\
\hline $\begin{array}{l}\text { c.2488C > T } \\
\text { (p.Arg830Trp) } \\
\text { c.10219G >A } \\
\text { (p.Ala3407Thr) (on } \\
\text { two alleles) }\end{array}$ & 1 & & 1 & $\begin{array}{l}\text { No } \\
\text { No }\end{array}$ & $\begin{array}{l}\text { VUS } \\
\text { VUS }\end{array}$ & $\begin{array}{l}\text { Snoeck [21] } \\
\text { Molenaar [36] }\end{array}$ \\
\hline $\begin{array}{l}\text { c. } 4178 \mathrm{~A}>\mathrm{G} \\
\text { (p.Lys1393Arg) } \\
\text { c. } 14210 \mathrm{G}>\mathrm{A} \\
\text { (p.Arg4737Gln) (on } \\
\text { two alleles) }\end{array}$ & 1 & & 1 & No & $\begin{array}{l}\text { VUS } \\
\text { Likely pathogenic }\end{array}$ & $\begin{array}{l}\text { Dlamini [5] } \\
\text { Monnier [37]; Gomez } \\
\text { [38] }\end{array}$ \\
\hline $\begin{array}{l}\text { c. } 4711 \mathrm{~A}>\mathrm{G} \\
(\mathrm{p} . \mathrm{Ile} 1571 \mathrm{Val}) \\
\text { c. } 10097 \mathrm{G}>\mathrm{A} \\
(\mathrm{p} . \text { Arg3366His) } \\
\text { c. } 11798 \mathrm{~A}>\mathrm{G} \\
\text { (p.Tyr3933Cys) (on } \\
\text { one allele) }\end{array}$ & 2 & 2 & & No & $\begin{array}{l}\text { VUS } \\
\text { VUS } \\
\text { VUS }\end{array}$ & $\begin{array}{l}\text { Tammaro [39]; Kraeva } \\
\text { [28] } \\
\text { Duarte [40]; Kraeva [28] } \\
\text { Gillies [41]; Kraeva [28] }\end{array}$ \\
\hline $\begin{array}{l}\text { c.6385G >A } \\
\text { (p.Asp2129Asn) }\end{array}$ & 1 & & 1 & No & VUS & Dlamini [5] \\
\hline $\begin{array}{l}\text { c. } 6502 \mathrm{G}>\mathrm{A} \\
\text { (p.Val2168Met) }\end{array}$ & 1 & 1 & & Yes & Pathogenic & Manning [42]; Girard [34] \\
\hline $\begin{array}{l}\text { c. } 6617 \mathrm{C}>\mathrm{T} \\
\text { (p.Thr2206Met) }\end{array}$ & 1 & 1 & & Yes & Pathogenic & $\begin{array}{l}\text { Manning [42]; Murayama } \\
\text { [43] }\end{array}$ \\
\hline $\begin{array}{l}\text { c.6838G > A } \\
\text { (p.Val2280Ile) }\end{array}$ & 1 & & 1 & No & Likely benign & Galli [44] \\
\hline $\begin{array}{l}\text { c. } 7025 \mathrm{~A}>\mathrm{G} \\
\quad(\text { p.Asn2342Ser })\end{array}$ & 2 & 1 & 1 & No & VUS $^{a}$ & Marchant [45]; Zullo [46] \\
\hline $\begin{array}{l}\text { c. } 7277 \mathrm{~A}>\mathrm{G} \\
\text { (p.Tyr2426Cys) }\end{array}$ & 1 & & 1 & No & VUS & Dlamini [5] \\
\hline $\begin{array}{l}\text { c.7300G > A } \\
\text { (p.Gly2434Arg) }\end{array}$ & 5 & 2 & 3 & Yes & Pathogenic & Keating [47]; Girard [34] \\
\hline $\begin{array}{l}\text { c. } 7304 \mathrm{G}>\mathrm{A} \\
\text { (p.Arg2435His) }\end{array}$ & 1 & 1 & & Yes & Pathogenic & Zhang [48]; Avila [49] \\
\hline $\begin{array}{l}\text { c. } 7361 \mathrm{G}>\mathrm{A} \\
\text { (p.Arg2454His) }\end{array}$ & 1 & 1 & & Yes & Pathogenic & $\begin{array}{l}\text { Barone [50]; Murayama } \\
\text { [43] }\end{array}$ \\
\hline $\begin{array}{l}\text { c. } 8054 \mathrm{C}>\mathrm{T} \\
\text { (p.Ser2685Phe) }\end{array}$ & 1 & & 1 & No & VUS & Scalco [51] \\
\hline
\end{tabular}


Table 2 (continued)

\begin{tabular}{|c|c|c|c|c|c|c|}
\hline Mutation & $\begin{array}{l}\text { Num- } \\
\text { ber of } \\
\text { patients }\end{array}$ & $\begin{array}{l}\text { Number of } \\
\text { patients with } \\
\text { MH }\end{array}$ & $\begin{array}{l}\text { Number of } \\
\text { patients with } \\
\text { RM }\end{array}$ & $\begin{array}{l}\text { (Allele with) } \\
\text { diagnostic MH } \\
\text { mutation }\end{array}$ & $\begin{array}{l}\text { Classification of patho- } \\
\text { genicity for MH (or for } \\
\text { congenital myopathy in } \\
\text { case of }^{\text {a) }} \text { ) }\end{array}$ & $\begin{array}{l}\text { Previous report of this } \\
\text { case } \\
\text { First report; functional } \\
\text { characterization }\end{array}$ \\
\hline $\begin{array}{l}\text { c. } 8327 \mathrm{C}>\mathrm{T} \\
\quad \text { (p.Ser2776Phe) }\end{array}$ & 1 & & 1 & No & Likely benign & This report \\
\hline $\begin{array}{l}\text { c. } 10219 \mathrm{G}>\mathrm{T} \\
\quad \text { (p.Ala3407Ser) }\end{array}$ & 1 & & 1 & No & VUS & Molenaar [36] \\
\hline $\begin{array}{l}\text { c. } 10616 \mathrm{G}>\mathrm{A} \\
\text { (p.Arg3539His) }\end{array}$ & 1 & 1 & & No & $\mathrm{VUS}^{\mathrm{a}}$ & Dekomien [52] \\
\hline $\begin{array}{l}\text { c. } 10681 \mathrm{G}>\mathrm{A} \\
\text { (p.Gly3561Arg) }\end{array}$ & 1 & & 1 & No & Likely pathogenic & This report \\
\hline $\begin{array}{l}\text { c.12861_12869dup } \\
\text { p.Thr4288_ } \\
\text { Ala4290dup }\end{array}$ & 3 & & 3 & No & VUS & Levano [53] \\
\hline $\begin{array}{l}\text { c. } 14545 \mathrm{G}>\mathrm{A} \\
\text { (p.Val4849Ile) }\end{array}$ & 9 & 9 & & Yes & Pathogenic & Jungbluth [6]; Merritt [54] \\
\hline $\begin{array}{l}\text { c. } 14545 \mathrm{G}>\mathrm{A} \\
\text { (p.Val4849Ile) } \\
\text { c.6961A > G } \\
\text { (p.Ile2321Val) }\end{array}$ & 1 & & 1 & $\begin{array}{l}\text { Yes } \\
\text { No }\end{array}$ & $\begin{array}{l}\text { Pathogenic } \\
\text { VUS }^{\mathrm{a}}\end{array}$ & $\begin{array}{l}\text { Jungbluth [55]; Merritt } \\
\text { [54] } \\
\text { Robinson [56] }\end{array}$ \\
\hline $\begin{array}{l}\text { c. } 14569 \mathrm{~T}>\mathrm{C} \\
\text { (p.Phe4857Leu) }\end{array}$ & 1 & 1 & & No & VUS & This report \\
\hline Total number of patients & 50 & 31 & 19 & & & \\
\hline
\end{tabular}

${ }^{\mathrm{a}}$ Reported as VUS in a autosomal recessive mode of inheritance

\section{Histopathological studies}

A total of 53 muscle biopsies (from 50 patients) were reviewed; in three patients two subsequent biopsies had been performed, at an interval of 4, 5 and 15 years, respectively. Ten biopsies were performed by needle (MH: $n=1$; RM: $n=9$ ), and 43 by open biopsy (MH: $n=31$; RM: $n=3$ ). Mean age at biopsy was 34 years (range 5-67 years).

Overall, $90 \%$ of the patients showed one or more of the following myopathic features, considered to be definitely abnormal but non-specific: increase in the number of fibres with internal nuclei $n=30$ of 50 patients $(60 \%)$ which were centralized in 18 patients (36\%), increased fibre size variation ( $n=44 ; 88 \%)$, and type I ( $\geq 55 \%)$ fibre predominance $(n=13 ; 26 \%)$ (Fig. 1b, c). Qualitative evaluation of the biopsies showed fibre type disproportion in patient 4,28 , 43, and 44 (for example: patient 4 in Fig. 2c). Furthermore, ring fibres were seen in four patients ( $8 \%$; patient 15, 16, 28 with MH and 45 with RM; Fig. 2b), and prominent intracellular lipid-droplets were observed in three patients with RM (patient 34, 36, 46; Fig. 1d). In two of them (patient 34, 46) the biopsy was taken within the first 2 weeks after the RM episode and the finding was considered secondary to propofol infusion on the Intensive Care Unit (ICU). Mild increase in endomysial connective tissue was observed in two patients (patient 20 with MH, 49 with RM). Five patients (10\%) had a normal biopsy (Fig. 1a), including four with MH (all with a pathogenic mutation) and one RM case (with a VUS).

Additional abnormalities on oxidative staining (generally considered to be more specific for $R Y R I$-related congenital myopathies) were observed in $52 \%$ of cases, and included unevenness (or 'moth-eaten appearance') $(n=24 ; 48 \%)$, central cores $(n=7 ; 14 \%)$, or multiple minicores $(n=3 ; 6 \%)$. In one patient the muscle biopsy showed features compatible with a rod-core myopathy (patient 29). The differences between the MH and RM groups were non-significant, except for the occurrence of unevenness on oxidative staining (more prevalent in $\mathrm{MH} ; p<0.01$ ), and the presence of intracellular lipid droplets $(p=0.02)$ and necrotic fibres $(p=0.02)$, more prevalent in patients with RM. Overall, the presence of cores neither correlated with muscle weakness nor with presence of (likely) pathogenic mutations. Furthermore, the cores were mostly located in the type 1 fibres and were almost all unstructured on electron microscopy. There was a high prevalence of cores in patients who carried the c. $1840 \mathrm{C}>\mathrm{T}$ mutation located at the RYRl N-terminus and classified as a diagnostic MH mutation by the EMHG (three of six patients). Taken together, there was a wide spectrum of histopathological abnormalities, ranging from mild increase in internal nuclei, fibre size variation and unevenness of oxidative staining to more overt core histopathology.

EM analysis could be performed in 26 patients and was abnormal in $22(85 \%)$; all of them had shown abnormalities 
Fig. 1 Histopathological features-haematoxylin \& eosin $(\mathrm{H} \& \mathrm{E})$ and Oil red $\mathrm{O}$ stain: features on $\mathrm{H} \& \mathrm{E}(\mathbf{a}-\mathbf{c})$ range from normal appearance (a Patient 7) to increased fibre size variability and an increase in internal nuclei (b Patient 6, and $\mathbf{c}$ Patient 4), many of them central (b). On Oil red O stain (d Patient 34), there is marked increase in intracellular lipid, probably related to the timing of the muscle biopsy in relation to the RM episode in the patient

Fig. 2 Histopathological features-oxidative stains and electron microscopy: abnormalities on oxidative stains range from mild unevenness of staining (a Patient 7) to overt cores and fibre type disproportion on NADH-TR stain (c Patient 4). Ring fibres (arrow) (b Patient 15) were noted in some cases. On electron microscopy, unstructured central cores (arrow) (d Patient 35) were occasionally noted. Size bar $=10 \mu \mathrm{m}$
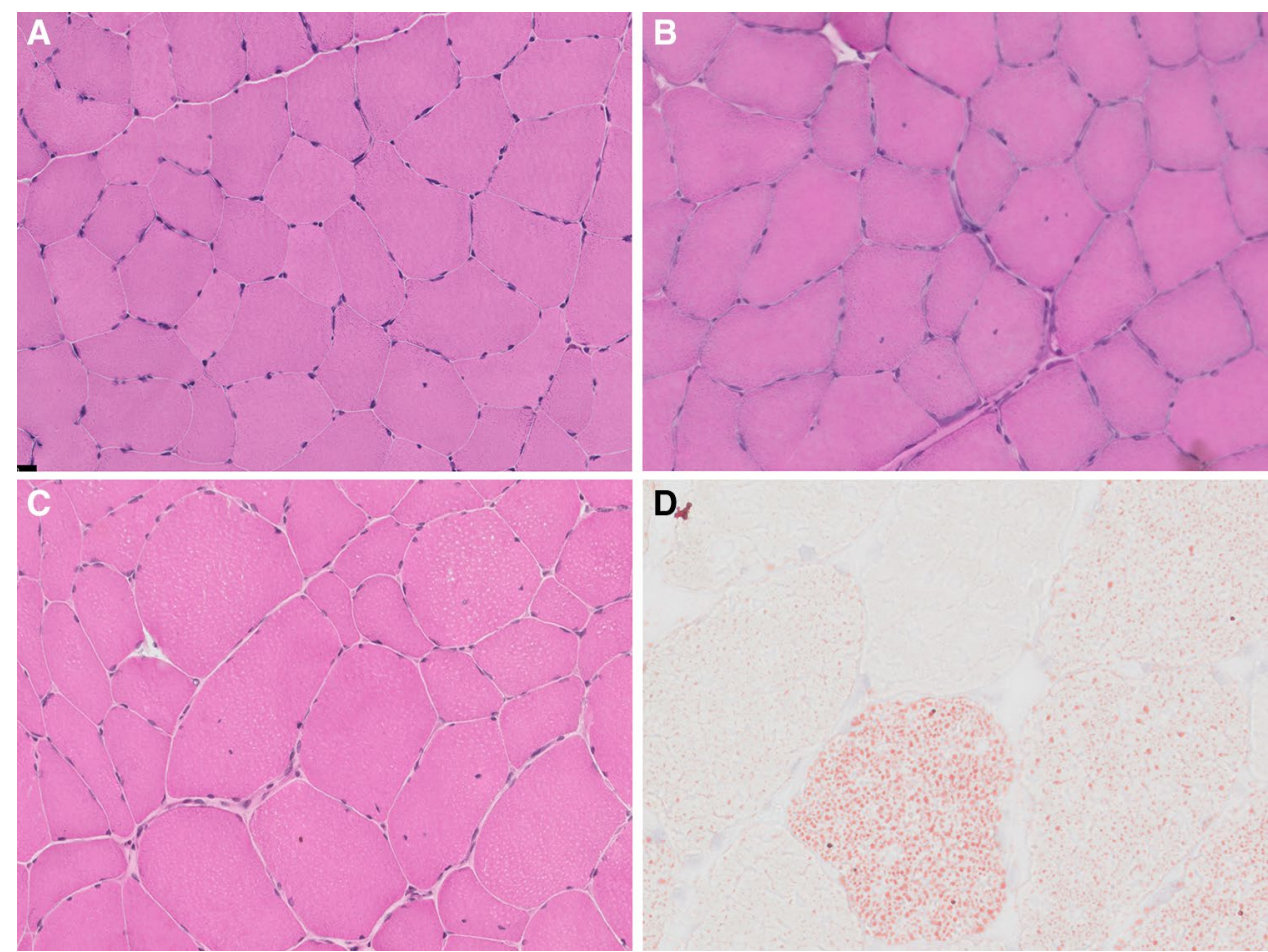

D.
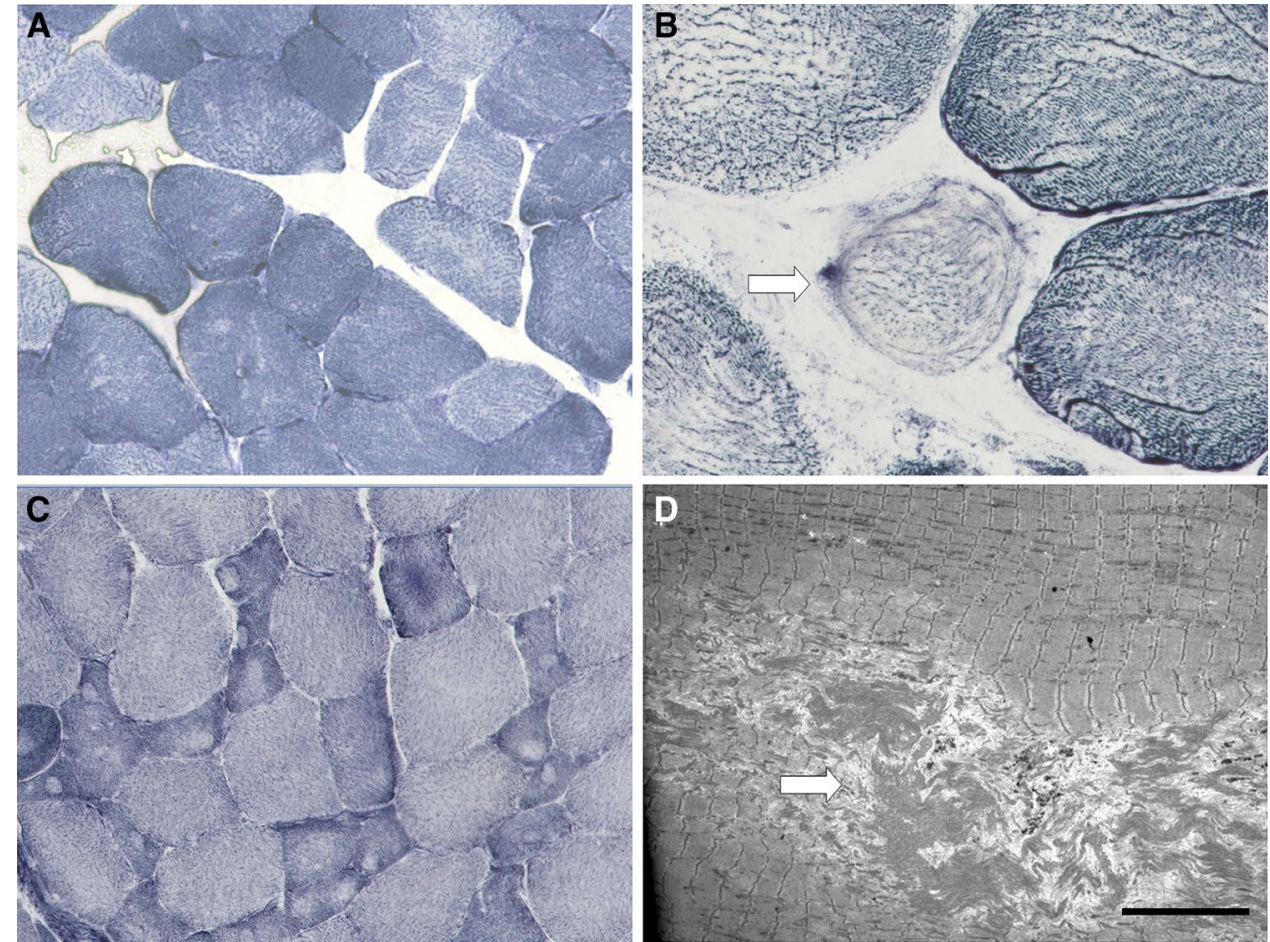

on light microscopy. Ultrastructural abnormalities included Z-band streaming $(n=8 ; 31 \%)$, cores of varying size $(n=8$; $31 \%$ ), altered mitochondria (e.g., enlargement, paracrystalline inclusions $n=4 ; 15 \%$ ), and increased lipid droplets $(n=1 ; 4 \%)$. The combined results of LM and EM showed cores in $28 \%$ of patients.

In three patients patient 10 (4 years interval), 38 (15 years interval) and 47 (5 years interval) sequential biopsies had been performed (both from the vastus lateralis). Biopsies in 
patient $10(\mathrm{MH})$ showed progression of myopathic features (increase of mild fibre-diameter variation and of internal nuclei), and emergence of oxidative staining abnormalities (mini-core-like morphology) over time. In patient 38 (RM and $\mathrm{MH}$ ) no significant changes were seen between the two biopsies (performed at age 41 and 59). The second biopsy (performed at age 18, 5 years later) in patient 47 was not available for review but evidence of multi-minicores was noted in the pathology report. Overall, the patients found to have cores on histopathological analysis tended to be slightly older than those without (mean age 37 versus 33 years, $p>0.05$ ).

Morphology varied among individuals with the same mutation, and there was no obvious genotype-phenotype correlation at the histopathological level. The most remarkable difference was observed between patients 32 and 33 (mother and daughter with RM, with RYRI p.G2434R; age at vastus lateralis biopsy 45 and 15 years, respectively) (Supplementary File 2). This might be related to the progression of morphological changes over time and/or variability of histopathological features between individuals with the same genetic background.

\section{Discussion}

The present retrospective multicentre study includes a total of 50 cases with $R Y R I$-related $\mathrm{MH}$ and/or RM, and represents the largest series reported to date describing the histopathological spectrum associated with these conditions. We found a broad spectrum of histopathological features, ranging from a normal muscle biopsy appearance (10\% of patients, MH: $n=4$; RM: $n=1$ ) to overtly myopathic changes, including those considered to be non-specific (in particular, and in order of decreasing frequency, an increase in fibre size variability, increase of internal nuclei, and type 1 fibre predominance), and, less frequently, those considered to be more closely associated with $R Y R I$-related myopathies (in particular, and in order of decreasing frequency, unevenness of oxidative stains, and more distinct central core and minicore structures, as well as, rarely, the combination of cores and rods).

These findings suggest that, whilst clearly leaning towards the milder end of the spectrum, RYRl-related $\mathrm{MH}$ and RM nevertheless form part of a histopathological continuum with the better-characterized $R Y R I$-related myopathies, including $\mathrm{CCD}, \mathrm{MmD}, \mathrm{CNM}$, and CFTD. Along the same lines, it is arguable that even some of the histopathological features considered to be non-specific, increase of internal or even central nuclei, increased fibre size variability, and type 1 fibre predominance may represent minor manifestations of well-recognized $R Y R I$-related congenital myopathies [3,
$4,57]$. Of note, similar mild myopathic manifestations have been previously reported in two other phenotypes closely linked to $\mathrm{MH}$-associated $R Y R 1$ mutations, the King-Denborough syndrome and late-onset axial myopathy $[9,58]$. Remarkably, histopathological features in RYRI-related $\mathrm{MH}$ and RM were not distinguishable, supporting our previous notion [5] that these are different but related manifestations due to genetically and functionally similar dominant $R Y R I$ gain-of-function mutations.

Other histopathological features not previously highlighted in RYRl-related disorders included the presence of sporadic ring fibres seen in four patients, two with $\mathrm{MH}$ and RM each. The significance of ring fibres, previously reported in $\mathrm{MH}$, is not known, although some have considered them an indicator of degeneration or regeneration [59]. Features of muscle degeneration and regeneration, however, were conspicuously absent in the cases studied, although developmental and fetal myosins were not studied. There was also no increase in fat and connective tissue, a feature which is common in severe early-onset $R Y R I$-related myopathies that may occasionally mimic a congenital muscular dystrophy, and may also relate to the part of the quadriceps sampled because of differential muscle involvement. Intracellular lipid droplets have not previously been reported in association with $R Y R 1$ mutations and were observed in three patients presenting with RM. Progression of muscle pathology, which has been noted in RYRl-related myopathies but also in one $\mathrm{MH}$ pedigree where muscle biopsies were performed at different ages [10,19], was observed in two of the three patients in whom subsequent biopsies had been performed.

Our findings also support the earlier observation that there is no direct correlation between muscle pathology (in particular, the presence of cores) and muscle weakness in $R Y R 1$-related myopathies: only one patient with mild muscle weakness had central cores, whereas five patients with mild proximal muscle weakness showed no core pathology at all (Supplementary File 1 and 2). Cores (both central and multiple minicores) were seen in $50 \%$ of patients with the $R Y R 1 \mathrm{~N}$-terminal $\mathrm{MH}$ mutation c. $1840 \mathrm{C}>\mathrm{T}$; it is uncertain if this reflects a specific genotype-phenotype correlation or is merely a co-incidental finding related to the relative high frequency of this causative MH mutation. The presence of mild weakness in patients originally referred for the investigation of MH suggests that some of these patients may in fact have had a mild RYRl-related myopathy, in cases where cores were present even fulfilling the criteria for either Central Core Disease (CCD) or Multi-minicore Disease $(\mathrm{MmD})$; this is an important observation emphasizing that $\mathrm{MH}$ patients could benefit from a formal assessment by a neurologist with experience in neuromuscular disorders, something which is currently not performed as a standard at all $\mathrm{MH}$ centres. 
Findings from our systematic muscle biopsy review focussing on the histopathological features of $R Y R I$-related $\mathrm{MH}$ and RM are supported by the few studies primarily focussing on clinical and genetic aspects of these presentations where such features have also been occasionally reported. The first larger case series on RYRI-related RM suggested similar non-specific but unequivocal changes, comprising increased variability in fibre size, increased internal nucleation and unevenness or core-like structures on oxidative stains in the few cases where this was studied $[5,15]$. Rueffert et al. reported histopathological changes in eight members of a large MH family carrying the RYRI c.6617C > T (p.Thr2206Met) mutation, all of them showing mild myopathic changes with isolated hypotrophic fibres and disseminated small areas with the reduction of oxidative staining ("multi-minicore like" lesions) [19]. In contrast, Orlov showed histopathological changes in only 28 of 86 (33\%) of genetically-confirmed $\mathrm{MH}$ patients [22]. Our recent retrospective study of 77 unrelated patients with $R Y R 1$-related disorders also included some histopathological data based on a review of 18 muscle biopsy reports (but not the original muscle biopsy slides) from patients with MH or RM, suggesting increase in internal nuclei (13/18, $72 \%)$, unevenness of oxidative staining $(10 / 18,56 \%)$ and increased fibre size variation in $(8 / 18,44 \%)$ as the most common histopathological features [21]. Fibre type I predominance, central cores, or multi-minicores were not reported, emphasizing the merit of our more extensive study exclusively focussing on RYRI-related $\mathrm{MH}$ and RM in a much larger cohort, and, most importantly, based on a systematic review of all muscle biopsies by the same neuromuscular pathologists.

Although the main emphasis of the present study was on the histopathological features of RYRI-related $\mathrm{MH}$ and RM, we gained some additional important insights, in particular concerning the relationship between clinical phenotypes, histopathological appearances, outcome of the IVCT, and genotype. The three MH patients with a positive IVCT had a normal muscle biopsy, whereas three patients with RM and a negative IVCT had an abnormal muscle biopsy with histopathological features suggestive of $R Y R I$ involvement. These findings are in line with previous reports showing absence of a correlation between the IVCT result and the presence of histopathological changes [21, 60, 61], and, more importantly, emphasize that at least in RYRl-related $\mathrm{RM}$, a diagnostic muscle biopsy may be as important as the IVCT for a comprehensive pathogenicity assessment of any $R Y R l$ variant of uncertain significance identified. Only four patients with $R Y R I$-related RM carry a diagnostic $R Y R I$ mutation according to the EMGH criteria, and the IVCT was positive in only two of the six patients tested, one of which was later retrospectively found to have a diagnostic MH mutation. Hence, in contrast to inconclusive genetic and normal IVCT results, a suggestive combination of histopathological features was more frequently indicative of $R Y R I$ involvement than the IVCT result.

Based on the observations outlined above, in cases where $R Y R 1$-related RM is suspected [51], we propose the following diagnostic steps: (1) RYRl Sanger sequencing (or preferably panel or exome sequencing to exclude other genetic causes of RM); (2) in case of a diagnostic MH mutation [i.e., a functionally characterized $R Y R 1$ mutation recognized as MH causative, as documented on the EMHG website (http:// www.emhg.org)], or an unequivocally pathogenic variant in another known RM-associated gene, no further tests need to be performed; where a diagnostic MH mutation is identified, the patient and his or her familiy needs to be counselled accordingly; (3) in case of a RYRl variant which has been associated with $\mathrm{MH}$ in the past but is not a diagnostic $\mathrm{MH}$ mutation as defined above, perform an IVCT to determine the $\mathrm{MH}$ risk with a functional study to prove causality as next step, and perform histopathological investigation; (4) in case of a $R Y R 1$ variant not previously associated with $\mathrm{MH}$, perform a diagnostic needle biopsy to evaluate the histopathological changes.

These diagnostic guidelines based on expert opinion emphasize the need for future research, in particular aimed at the large-scale functional characterization of RYRI variants implicated in RM, and the importance of international collaborative mutational databases to establish clinico-pathological genotype-phenotype correlations for RM and other $R Y R 1$-related disorders in larger cohorts, ultimately reducing the need for invasive investigations such as a muscle biopsy [62].

The main limitations of this study are its partly retrospective design, resulting in missing data for several patients and only qualitative data for certain features, and the fact that the pathologists reviewing the muscle biopsies were not blinded to the genetic diagnosis. Another limitation is the absence of data on age-matched control subjects, largely reflecting the fact that data on muscle histology in healthy controls are limited. We recently included 12 healthy subjects as controls in a study on inclusion body myositis and observed mild myopathic features (increase of fibre size variation and of internal nuclei) in at least half of them. However, the subjects were older than the patients in this current study (mean age 54 years versus 34 years), which is likely to be relevant considering that age-related muscle decline has been recognized to start only from the fifth decade (Lassche, personal communication) [63]. Despite these shortcomings, we do think that the results of the present study offer valid preliminary and robust insights into the histopathological spectrum of MH and RM. With regards to future work, the diagnostic value of the muscle biopsies in this context should preferably be tested systematically in a prospective study with blinded 
pathology reviewers and well-defined quantitative criteria, and, if feasible, biopsies from age-matched control subjects.

In conclusion, our findings illustrate that RYRl-related $\mathrm{MH}$ and RM show a very similar histopathological spectrum, ranging from non-specific findings to features considered to be more suggestive of $R Y R I$-related congenital myopathies such as central nuclei, central cores, multiple mini-cores and unevenness of oxidative staining. Although many of those features are often considered non-specific when occurring in isolation, their common occurrence should raise the suspicion of a RYRI-related disorder, and/or support the likelihood of causality where $R Y R I$ variants of only uncertain pathogenicity have been identified in a patient. Until more robust methods of functional characterization and/or largescale genotype-phenotype data will become available, (needle) muscle biopsy will remain an additional but essential tool in the ascertainment of presumed $R Y R I$-related RM.

Acknowledgements We are grateful to the European Neuromuscular Centre and the RYR-1 foundation who sponsored the 217th ENMC International Workshop: RYRl-related myopathies, in Naarden, The Netherlands, 29-31 January 2016. The discussion during this meeting enabled the design of this retrospective study.

\section{Compliance with ethical standards}

Conflicts of interest On behalf of all authors, the corresponding author states that there is no conflict of interest.

Ethical standards All studies in this review have been approved by the appropriate ethics committee and have therefore been performed in accordance with the ethical standards laid down in the 1964 Declaration of Helsinki and its later amendments.

Open Access This article is distributed under the terms of the Creative Commons Attribution 4.0 International License (http://creativeco mmons.org/licenses/by/4.0/), which permits unrestricted use, distribution, and reproduction in any medium, provided you give appropriate credit to the original author(s) and the source, provide a link to the Creative Commons license, and indicate if changes were made.

\section{References}

1. Jungbluth H, Treves S, Zorzato F, Sarkozy A, Ochala J, Sewry C et al (2018) Congenital myopathies: disorders of excitation-contraction coupling and muscle contraction. Nat Rev Neurol

2. Jungbluth $\mathrm{H}$, Zhou H, Hartley L, Halliger-Keller B, Messina S, Longman $\mathrm{C}$ et al (2005) Minicore myopathy with ophthalmoplegia caused by mutations in the ryanodine receptor type 1 gene. Neurology 65(12):1930-1935

3. Wilmshurst JM, Lillis S, Zhou H, Pillay K, Henderson H, Kress W et al (2010) RYR1 mutations are a common cause of congenital myopathies with central nuclei. Ann Neurol 68(5):717-726

4. Clarke NF, Waddell LB, Cooper ST, Perry M, Smith RL, Kornberg AJ et al (2010) Recessive mutations in RYR1 are a common cause of congenital fiber type disproportion. Hum Mutat 31(7):E1544-E1550
5. Dlamini N, Voermans NC, Lillis S, Stewart K, Kamsteeg EJ, Drost G et al (2013) Mutations in RYR1 are a common cause of exertional myalgia and rhabdomyolysis. Neuromuscul Disord 23(7):540-548

6. Zhou H, Lillis S, Loy RE, Ghassemi F, Rose MR, Norwood F et al (2010) Multi-minicore disease and atypical periodic paralysis associated with novel mutations in the skeletal muscle ryanodine receptor (RYR1) gene. Neuromuscul Disord 20(3):166-173

7. Matthews E, Neuwirth C, Jaffer F, Scalco RS, Fialho D, Parton $M$ et al (2018) Atypical periodic paralysis and myalgia: A novel RYR1 phenotype. Neurology 90(5):e412-e418

8. Jungbluth H, Cullup T, Lillis S, Zhou H, Abbs S, Sewry C et al (2010) Centronuclear myopathy with cataracts due to a novel dynamin 2 (DNM2) mutation. Neuromuscul Disord 20(1):49-52

9. Loseth S, Voermans NC, Torbergsen T, Lillis S, Jonsrud C, Lindal S et al (2013) A novel late-onset axial myopathy associated with mutations in the skeletal muscle ryanodine receptor (RYR1) gene. J Neurol 260(6):1504-1510

10. Sewry CA, Muller C, Davis M, Dwyer JS, Dove J, Evans G et al (2002) The spectrum of pathology in central core disease. Neuromuscul Disord NMD 12(10):930-938

11. Bevilacqua JA, Monnier N, Bitoun M, Eymard B, Ferreiro A, Monges S et al (2011) Recessive RYR1 mutations cause unusual congenital myopathy with prominent nuclear internalization and large areas of myofibrillar disorganization. Neuropathol Appl Neurobiol 37(3):271-284

12. Abath Neto O, Moreno CAM, Malfatti E, Donkervoort S, Bohm J, Guimaraes JB et al (2017) Common and variable clinical, histological, and imaging findings of recessive RYR1-related centronuclear myopathy patients. Neuromuscul Disord NMD 27(11):975-985

13. Hausman R (1973) Muscle changes in malignant hyperthermia. J Pathol 110(3):Pv-vi

14. Gadoth N, Margalit D, Shapira Y (1978) Myopathy with multiple central cores. A case with hypersensitivity to pyrexia. Neuropadiatrie 9(3):239-244

15. Harriman DG (1988) Malignant hyperthermia myopathy—a critical review. Br J Anaesth 60(3):309-316

16. Heiman-Patterson T, Fletcher JE, Rosenberg H, Tahmoush AJ (1987) No relationship between fiber type and halothane contracture test results in malignant hyperthermia. Anesthesiology 67(1):82-84

17. Figarella-Branger D, Kozak-Ribbens G, Rodet L, Aubert M, Borsarelli J, Cozzone PJ et al (1993) Pathological findings in 165 patients explored for malignant hyperthermia susceptibility. Neuromuscul Disord 3(5-6):553-556

18. von Breunig F, Wappler F, Hagel C, von Richthofen V, Fiege M, Weisshorn R et al (2004) Histomorphologic examination of skeletal muscle preparations does not differentiate between malignant hyperthermia-susceptible and -normal patients. Anesthesiology 100(4):789-794

19. Rueffert H, Wehner M, Ogunlade V, Meinecke C, Schober R (2009) Mild clinical and histopathological features in patients who carry the frequent and causative malignant hyperthermia RyR1 mutation p.Thr2206Met. Clin Neuropathol 28(6):409-416

20. Klingler W, Rueffert H, Lehmann-Horn F, Girard T, Hopkins PM (2009) Core myopathies and risk of malignant hyperthermia. Anesth Analg 109(4):1167-1173

21. Snoeck M, van Engelen BG, Kusters B, Lammens M, Meijer R, Molenaar JP et al (2015) RYR1-related myopathies: a wide spectrum of phenotypes throughout life. Eur J Neurol 22(7):1094-1112

22. Orlov D, Keith J, Rosen D, Croul S, Kraeva N, Riazi S (2013) Analysis of histomorphology in malignant hyperthermia-susceptible patients. Can J Anaesth 60(10):982-989 
23. Scalco RS, Gardiner AR, Pitceathly RD, Zanoteli E, Becker J, Holton JL et al (2015) Rhabdomyolysis: a genetic perspective. Orphanet J Rare Dis 10:51

24. Strande NT, Brnich SE, Roman TS, Berg JS (2018) Navigating the nuances of clinical sequence variant interpretation in Mendelian disease. Genet Med

25. Richards S, Aziz N, Bale S, Bick D, Das S, Gastier-Foster J et al (2015) Standards and guidelines for the interpretation of sequence variants: a joint consensus recommendation of the American College of Medical Genetics and Genomics and the Association for Molecular Pathology. Genet Med 17(5):405-424

26. Dubowitz V. Sewry C, Anders O (2013) Muscle biopsy: a practical approach

27. Scalco RS, Snoeck M, Quinlivan R, Treves S, Laforet P, Jungbluth $\mathrm{H}$ et al (2016) Exertional rhabdomyolysis: physiological response or manifestation of an underlying myopathy? BMJ Open Sport Exerc Med 2(1):e000151

28. Kraeva N, Heytens L, Jungbluth H, Treves S, Voermans N, Kamsteeg E et al (2015) Compound RYR1 heterozygosity resulting in a complex phenotype of malignant hyperthermia susceptibility and a core myopathy. Neuromuscul Disord 25(7):567-576

29. Quane KA, Keating KE, Manning BM, Healy JM, Monsieurs K, Heffron JJ et al (1994) Detection of a novel common mutation in the ryanodine receptor gene in malignant hyperthermia: implications for diagnosis and heterogeneity studies. Hum Mol Genet $3(3): 471-476$

30. Tong J, Oyamada H, Demaurex N, Grinstein S, McCarthy TV, MacLennan DH (1997) Caffeine and halothane sensitivity of intracellular $\mathrm{Ca} 2+$ release is altered by 15 calcium release channel (ryanodine receptor) mutations associated with malignant hyperthermia and/or central core disease. J Biol Chem 272(42):26332-26339

31. Tammaro A, Bracco A, Cozzolino S, Esposito M, Di Martino A, Savoia G et al (2003) Scanning for mutations of the ryanodine receptor (RYR1) gene by denaturing HPLC: detection of three novel malignant hyperthermia alleles. Clin Chem 49(5):761-768

32. Sato K, Roesl C, Pollock N, Stowell KM (2013) Skeletal muscle ryanodine receptor mutations associated with malignant hyperthermia showed enhanced intensity and sensitivity to triggering drugs when expressed in human embryonic kidney cells. Anesthesiology 119(1):111-118

33. Gillard EF, Otsu K, Fujii J, Khanna VK, de Leon S, Derdemezi $\mathrm{J}$ et al (1991) A substitution of cysteine for arginine 614 in the ryanodine receptor is potentially causative of human malignant hyperthermia. Genomics 11(3):751-755

34. Girard T, Urwyler A, Censier K, Mueller CR, Zorzato F, Treves S (2001) Genotype-phenotype comparison of the Swiss malignant hyperthermia population. Hum Mutat 18(4):357-358

35. Guis S, Figarella-Branger D, Monnier N, Bendahan D, KozakRibbens G, Mattei JP et al (2004) Multiminicore disease in a family susceptible to malignant hyperthermia: histology, in vitro contracture tests, and genetic characterization. Arch Neurol 61(1):106-113

36. Molenaar JP, Voermans NC, van Hoeve BJ, Kamsteeg EJ, Kluijtmans LA, Kusters B et al (2014) Fever-induced recurrent rhabdomyolysis due to a novel mutation in the ryanodine receptor type 1 gene. Intern Med J 44(8):819-820

37. Monnier N, Kozak-Ribbens G, Krivosic-Horber R, Nivoche Y, Qi $\mathrm{D}, \mathrm{Kraev} \mathrm{N}$ et al (2005) Correlations between genotype and pharmacological, histological, functional, and clinical phenotypes in malignant hyperthermia susceptibility. Hum Mutat 26(5):413-425

38. Gomez AC, Holford TW, Yamaguchi N (2016) Malignant hyperthermia-associated mutations in the S2-S3 cytoplasmic loop of type 1 ryanodine receptor calcium channel impair calcium-dependent inactivation. Am J Physiol Cell Physiol 311(5):C749-C757
39. Tammaro A, Di Martino A, Bracco A, Cozzolino S, Savoia G, Andria B et al (2011) Novel missense mutations and unexpected multiple changes of RYR1 gene in 75 malignant hyperthermia families. Clin Genet 79(5):438-447

40. Duarte ST, Oliveira J, Santos R, Pereira P, Barroso C, Conceicao I et al (2011) Dominant and recessive RYR1 mutations in adults with core lesions and mild muscle symptoms. Muscle Nerve 44(1):102-108

41. Gillies RL, Bjorksten AR, Davis M, Du Sart D (2008) Identification of genetic mutations in Australian malignant hyperthermia families using sequencing of RYR1 hotspots. Anaesth Intensive Care 36(3):391-403

42. Manning BM, Quane KA, Ording H, Urwyler A, Tegazzin V, Lehane $M$ et al (1998) Identification of novel mutations in the ryanodine-receptor gene (RYR1) in malignant hyperthermia: genotype-phenotype correlation. Am J Hum Genet 62(3):599-609

43. Murayama T, Kurebayashi N, Ogawa H, Yamazawa T, Oyamada H, Suzuki J et al (2016) Genotype-phenotype correlations of malignant hyperthermia and central core disease mutations in the central region of the RYR1 channel. Hum Mutat 37(11):1231-1241

44. Galli L, Orrico A, Cozzolino S, Pietrini V, Tegazzin V, Sorrentino V (2002) Mutations in the RYR1 gene in Italian patients at risk for malignant hyperthermia: evidence for a cluster of novel mutations in the C-terminal region. Cell Calcium 32(3):143-151

45. Marchant CL, Ellis FR, Halsall PJ, Hopkins PM, Robinson RL (2004) Mutation analysis of two patients with hypokalemic periodic paralysis and suspected malignant hyperthermia. Muscle Nerve 30(1):114-117

46. Zullo A, Klingler W, De Sarno C, Ferrara M, Fortunato G, Perrotta $\mathrm{G}$ et al (2009) Functional characterization of ryanodine receptor (RYR1) sequence variants using a metabolic assay in immortalized B-lymphocytes. Hum Mutat 30(4):E575-E590

47. Keating KE, Quane KA, Manning BM, Lehane M, Hartung $\mathrm{E}$, Censier K et al (1994) Detection of a novel RYR1 mutation in four malignant hyperthermia pedigrees. Hum Mol Genet 3(10): $1855-1858$

48. Zhang Y, Chen HS, Khanna VK, De Leon S, Phillips MS, Schappert K et al (1993) A mutation in the human ryanodine receptor gene associated with central core disease. Nat Genet 5(1):46-50

49. Avila G, Dirksen RT (2001) Functional effects of central core disease mutations in the cytoplasmic region of the skeletal muscle ryanodine receptor. J Gen Physiol 118(3):277-290

50. Barone V, Massa O, Intravaia E, Bracco A, Di Martino A, Tegazzin V et al (1999) Mutation screening of the RYR1 gene and identification of two novel mutations in Italian malignant hyperthermia families. J Med Genet 36(2):115-118

51. Scalco RS, Voermans NC, Piercy RJ, Jungbluth H, Quinlivan R (2016) Dantrolene as a possible prophylactic treatment for RYR1related rhabdomyolysis. Eur J Neurol 23(8):e56-e57

52. Dekomien G, Gencik M, Gencikova A, Klenk Y, Epplen JT (2005) Gene symbol: RYR1. Disease: malignant hyperthermia. Hum Genet 118(3-4):543

53. Levano S, Vukcevic M, Singer M, Matter A, Treves S, Urwyler A et al (2009) Increasing the number of diagnostic mutations in malignant hyperthermia. Hum Mutat 30(4):590-598

54. Merritt A, Booms P, Shaw MA, Miller DM, Daly C, Bilmen JG et al (2017) Assessing the pathogenicity of RYR1 variants in malignant hyperthermia. Br J Anaesth 118(4):533-543

55. Jungbluth $\mathrm{H}$, Muller CR, Halliger-Keller B, Brockington M, Brown SC, Feng L et al (2002) Autosomal recessive inheritance of RYR1 mutations in a congenital myopathy with cores. Neurology 59(2):284-287

56. Robinson R, Carpenter D, Shaw MA, Halsall J, Hopkins P (2006) Mutations in RYR1 in malignant hyperthermia and central core disease. Hum Mutat 27(10):977-989 
57. Sato I, Wu S, Ibarra MC, Hayashi YK, Fujita H, Tojo M et al (2008) Congenital neuromuscular disease with uniform type 1 fiber and RYR1 mutation. Neurology 70(2):114-122

58. Dowling JJ, Lillis S, Amburgey K, Zhou H, Al-Sarraj S, Buk SJ et al (2011) King-Denborough syndrome with and without mutations in the skeletal muscle ryanodine receptor (RYR1) gene. Neuromuscul Disord 21(6):420-427

59. Kitagawa Y, Sato J, Kuriyama M, Sano K, Hashimoto K (2011) Ring fibers visualized by electron microscopy in a Japanese patient with malignant hyperthermia. Odontology 99(1):101-104

60. Wappler F, Fiege M, Steinfath M, Agarwal K, Scholz J, Singh S et al (2001) Evidence for susceptibility to malignant hyperthermia in patients with exercise-induced rhabdomyolysis. Anesthesiology 94(1):95-100

61. Carpenter D, Ismail A, Robinson RL, Ringrose C, Booms P, Iles DE et al (2009) A RYR1 mutation associated with recessive congenital myopathy and dominant malignant hyperthermia in Asian families. Muscle Nerve 40(4):633-639

62. Jungbluth H, Dowling JJ, Ferreiro A, Muntoni F, Consortium RYRM (2016) 217th ENMC international workshop: RYR1related myopathies, Naarden, The Netherlands, 29-31 January 2016. Neuromuscul Disord 26(9):624-633

63. Curtis E, Litwic A, Cooper C, Dennison E (2015) Determinants of muscle and bone aging. J Cell Physiol 230(11):2618-2625

\section{Affiliations}

\section{G. J. Knuiman ${ }^{1}$ - B. Küsters ${ }^{1}$ - L. Eshuis ${ }^{1}$ - M. Snoeck ${ }^{2} \cdot$ M. Lammens $^{3} \cdot$ L. Heytens $^{4}$ • W. De Ridder ${ }^{5,6,7}$. J. Baets ${ }^{5,6,7}$. R. S. Scalco ${ }^{8}$ R. Quinlivan ${ }^{8}$. J. Holton ${ }^{8} \cdot$ I. Bodi $^{9}$. E. Wraige ${ }^{9} \cdot$ A. Radunovic ${ }^{10}$. C. von Landenberg ${ }^{11}$. J. Reimann ${ }^{11}$. E.-J. Kamsteeg ${ }^{12} \cdot$ C. Sewry ${ }^{13} \cdot$ H. Jungbluth ${ }^{9,14,15} \cdot$ N. C. Voermans ${ }^{16}$}

1 Department of Pathology, Radboud University Medical Centre, Nijmegen, The Netherlands

2 National MH Investigation Unit, Department of Anaesthesiology, Canisius Wilhelmina Hospital, Nijmegen, The Netherlands

3 Department of Pathology, Antwerp University Hospital, University of Antwerp, Edegem, Belgium

4 Malignant Hyperthermia Research Unit, University of Antwerp, Antwerp, Belgium

5 Neurogenetics Group, Center for Molecular Neurology, VIB, Antwerp, Belgium

6 Laboratory of Neuromuscular Pathology, Institute Born-Bunge, University of Antwerp, Antwerp, Belgium

7 Department of Neurology, Neuromuscular Reference Centre, Antwerp University Hospital, Antwerp, Belgium

8 MRC Centre for Neuromuscular Diseases, Institute of Neurology, University College London, London, UK
9 Department of Paediatric Neurology, Neuromuscular Service, Evelina Children's Hospital, Guy's and St Thomas' Hospital NHS Foundation Trust, London, UK

10 Barts Neuromuscular Diseases Centre, Royal London Hospital, London, UK

11 Muscle Lab, Department of Neurology, University of Bonn Medical Centre, Bonn, Germany

12 Department of Human Genetics, Radboud University Medical Centre, Nijmegen, The Netherlands

13 Dubowitz Neuromuscular Centre, UCL Institute of Child Health and Great Ormond Street Hospital for Children, London, UK

14 Muscle Signalling Section, Randall Division for Cell and Molecular Biophysics, King's College, London, UK

15 Department of Basic and Clinical Neuroscience, King's College, IoPPN, London, UK

16 Department of Neurology, Radboud University Medical Centre, Nijmegen, The Netherlands 